\title{
Precision Flow-Monitoring Spectrometer \\ with Low Noise and High Stability
}

\author{
by \\ Brian A. Bidlingmeyer and Stanley N. Deming ${ }^{I}$ \\ Department of Chemistry \\ Purdue University \\ Lafayette, Indiana 47907
}

$\begin{aligned}{ }^{1} \text { Present Address: } & \text { Department of Chemistry } \\ & \text { Emory University } \\ & \text { Atlanta, Georgia } 30322\end{aligned}$

This report was prepared as an account of work sponsored by the United States Government. Neither the United States nor the United States Atomic Energy Commission, nor any of their employees, nor any of their contractors, subcontractors, or their employees, makes any warranty, express or implied, or assumes any legal liability or responsibility for the accuracy, completeness or usefulness of any information, apparatus, product or process disclosed, or represents that its use would not infringe privately owned rights. 


\section{DISCLAIMER}

This report was prepared as an account of work sponsored by an agency of the United States Government. Neither the United States Government nor any agency Thereof, nor any of their employees, makes any warranty, express or implied, or assumes any legal liability or responsibility for the accuracy, completeness, or usefulness of any information, apparatus, product, or process disclosed, or represents that its use would not infringe privately owned rights. Reference herein to any specific commercial product, process, or service by trade name, trademark, manufacturer, or otherwise does not necessarily constitute or imply its endorsement, recommendation, or favoring by the United States Government or any agency thereof. The views and opinions of authors expressed herein do not necessarily state or reflect those of the United States Government or any agency thereof. 


\section{DISCLAIMER}

Portions of this document may be illegible in electronic image products. Images are produced from the best available original document. 
INTRODUCTION

The use of liquid chromatography as an efficient and rapid technique for separation and accurate analysis is clearly in evidence. $(1,2)$ The precise and accurate detection of small amounts of separated compounds places stringent requirements upon the detection system used. Short-term noise and baseline drift must be minimal for reliable observation of tiny peaks and for accurate integration of peak areas.

Because there is presently no universal detector of high stability and high sensitivity, it is necessary to select a detector that will respond to the characteristics of the specific compounds being separated. Many compounds of interest absorb visible radiation or can be reacted to form compounds that absorb in this region of the spectrum. Thus, in many instances, a visible spectrometer possessing high stability and low noise would be a suitable monitor of the effluent stream from a liquid chromatograph. Furthermore, it has been pointed out that a single beam spectrophotometer with $\% \mathrm{~T}$ output will meet the demands for a detector in high speed liquid chromatography and perform as well as a more sophisticated instrument having a logarithmic amplifier. (3)

Recently, Pardue and Deming (4) used optical feedback to modify a Bausch and Lomb Spectronic 20 spectrometer. The resulting instrument possessed high stability and low noise and was capable of continuous wavelength variation between 400 and $625 \mathrm{~nm}$. This report describes a further modification that results in a durable, inexpensive, high-precision, flow-monitoring detector. The limits of detection were determined for the solute methyl orange, as eluted from a chromatographic column using silica gel as an adsorbent. 
EXPERIMENTAL

Spectrometer Modifications. All original electronics in the spectronic 20 were disconnected. External leads were provided to the bulb and phototubes. Both sample and control phototubes were IP39 (S-4 response) and were mounted in the phototube housings of the unmodified Spectronic 20. The original cuvet holder was removed and a $100 \mathrm{\mu l}$ flow cell (Fischer Scientific, Chicago, IIl.) was mounted in its place.

Rigid mounting of the bulb proved to be one of the most critical factors affecting stability and noise level. Rigidity was achieved by bracing the bulb against the lens collimating tube; the original bulb mount was used. Further bulb positioning was necessary to focus the entire filament on the center of the grating. Improper centering reaulted in large noise levels.

The mechanical " $100 \%$ " control was not used. All internal surfaces of the spectrometer were sprayed with ultra-flat black paint (Krylon, No. 1602, Borden, Inc., New York, N.Y.) to minimize stray light. The entire spectrometer was placed in an insulating box to increase the thermal time constant of the instrument. Instrument warm-up was approximately five hours to achieve maximum stability.

Details of the electronic circuit are shown in Fig. I. The manner of control has been discussed in detail previously (5). The lamp filament is viewed from two sides, as it is in the original Spectronic 20. This arrangement is in contrast to other optically' stabilized photometers that utilize a beam splitter $(4,5)$. The 
radiation emitted from one side of the filament goes directly to the control phototube producing a current which is compared to a constant current source. Any variation in light is integrated by the operational amplifier, which, in turn, drives the programmable power supply to compensate for the intensity change. Light from the other side of the filament is collimated, diffracted, passed through the sample, and detected by the sample phototube. The variable resistive and capacitive feedback of the sample amplifier allows the attainment of $1.0000 \mathrm{~V}$ as the $100.00 \% \mathrm{~T}$ for all wavelengths desired.

Zero-suppression was accomplished by bucking the output of the sample amplifier with a constant-voltage supply. A variable range strip-chart recorder (Model SRL, Sargent-Welch, Skokie, III.) provided the capability of scale expansion.

Chromatographic System. Methyl orange (Eastman Organic Chemicals, Rochester, N.Y.) was recrystallized twice from distilled water yielding a purified dye with a molar absorptivity of $2.5 \times 10^{4}$ Iiter mole $\mathrm{cm}^{-1}$. Water was distilled and then deionized through a mixed anion-cation exchange resin (Amberlite MB-3). Davison 58 silica gel (105-125 H, W. R. Grace, Baltimore, Md.) was used as the solid chromatographic support.

The silica gel was placed in water and degassed under vacuum for one hour. Following degassing, the gel was slurry-packed with vibration into a $0.6-\mathrm{cm}$ i.d. X 30-cm glass column. Beckman fittings (Beckman Instruments, Fullerton, Calif.) were used as inlet and exit connections (6). The inlet was a "tee" fitting through which samples were introduced with a syringe. The column exit contained a nylon mesh cloth (Glenco Scientific, Houston, 
Texas) tightly placed across the exit tube $(0.51-\mathrm{mm}$ i.d.). The cloth served as the bed support and reduced the dead volume usually present when a glass wool plug is used as the gel support. Water was used as the eluting solvent and was thermally degassed with an infrared lamp before pumping. A mini-pump (Milton Roy, Dayton, Ohio) provided the flow.

\section{RESULTS AIND DISCUSSION}

Spectrometer Characteristics. The spectral response of the photometer was found to be the same as in the beam-split instrument (4), the general shape of the response curve resembling a Gaussian with a maximum at $525 \mathrm{~nm}$ and cut-offs at 360 and $670 \mathrm{~nm}$. Long-term noise was observed at 425,464, and $550 \mathrm{~nm}$ and found to be less than $0.02 \% \mathrm{~T}$ per hour. A typical recording trace is shown in Fig. 2. At a flow rate of $0.50 \mathrm{ml} \mathrm{min}^{-1}$ through a silica gel column, the drift was $0.0125 \% \mathrm{~T}(0.00005 \mathrm{~A} . \mathrm{U}$. at $100 \% \mathrm{~T})$ for the 35 -minute period. During a 12-hour stability run with distilled water flowing through the cell at a rate of $0.50 \mathrm{ml} \mathrm{min}^{-1}$, the drift was less than $\pm 0.02 \% \mathrm{~T}( \pm 0.00009$ A.U. at $100 \% \mathrm{~T})$ per hour and occurred in a slow oscillatory fashion with a period of approximately two hours. When compared to the modified spectrophotometer, of Pardue and Deming (4) it is clear that the elimination of the beam splitter did not affect the stability or sensitivity of the instrument. The performance of this visible unit is also comparable to that of an ultraviolet detector previously reported (7).

Figure 3 illustrates the linearity and lower limits of detection for methyl orange. Peak area in units of A.U.-sec 
is usually a linear function of concentration. Over small ranges of absorbance, $\% \mathrm{~T}$ is approximately a linear function of absorbance. Thus, peak area in units of \% T-sec approaches a linear function of concentration as the observed $\% \mathrm{~T}$ full scale decreases. Recorder sensitivity was $1.25 \%$ T per vertical $\mathrm{cm}$ and $0.042 \mathrm{sec}$ per horizontal $\mathrm{cm}(2.54 \mathrm{~cm}$ per minute) on the chart paper. Peak area in $\mathrm{cm}^{2}$ is plotted as a function of the concentration of methyl orange in the sample ( $1.00 \mu \mathrm{l}$ in each case). Each point on the graph represents a complete experiment. Peak areas were determined with a $K$ \& $E$ planimeter. Each peak was traced in triplicate and the average taken as the value for the peak area. The average standard deviation in determining peak areas was $0.433 \mathrm{~cm}^{2}$. The standard error of estimate of the twelve points in Fig. 3 is $0.74 \mathrm{~cm}^{2}$ corresponding to $2.4 \times 10^{-6}$ mole liter ${ }^{-1}$ methyl orange in a . $1.00 \mathrm{\mu l}$ sample. This indicates that $2.3 \mathrm{ng}$ of methyl orange may be detected with $99 \%$ confidence.

It is apparent that chromatographic peaks containing extremely small amounts of solute can be determined easily with this detector. The only limitation is that the compound have a visible absorption of moderate absorptivity. The utility of the photometer should be wide, particularly for biological and pharmaceutical interests: The high stability, sensitivity, and reproducibility make the instrument advantageous for possible quantitation in trace analysis. 
SUMMARY

A Bausch and Lomb Spectronic 20 has been modified to monitor chromatographic columns with high precision and stability. The system employs optical feedback to maintain the source intensity at a constant level. With solvent flowing through the detector the short-term noise is less than \pm 0.00005 A.U. (at 100\% T) and drift is \pm 0.00009 A.U. (at $100 \% \mathrm{~T}$ ) per hour. The utility of the spectrometer is illustrated with the detection of methyl orange eluted from a chromatographic column. In this particular case, $2.3 \mathrm{ng}$ can be detected with $99 \%$ confidence. 


\section{ACKNOWLEDGEMENT}

The authors wish to thank L. B. Rogers of Purdue University for suggestions in preparation of this manuscript. This work was supported, in part, by funds from the Atomic Energy Commission under contract $\operatorname{AT}(11-1)-1222$. 
REFERENCES

I. Horvath, C., Lipsky, S. R., Anal. Chem. 4I, 1227 (1969).

2. Scott, C. D., Attril, J. E., and Anderson, N. G., Proc. Soc. Expt1. Biol. Med. 125, I8I (1967).

3. Deininger, G., Kroneisen, A., Halasz, I., Chromatogrophia I, 329 (1970).

4. Pardue, H. L., and Deming, S. N., Anal. Chem. 41, 986 (1969).

5. Pardue, H. L. and Rodriquez, P. A., Anal. Chem. 39, 901 (1967).

6. Neddermeyer, P. A., and Rogers, I. B., Anal. Chem. 40, 955 (1968).

7. Kirkland, J. J., Anal. Chem. 40, 391 (1968). 


\section{List of Captions}

Figure 1. Schematic diagram of modified photometer.

Figure 2. Short-term stability and noise

Wavelength: $464 \mathrm{~nm}$

Sample amplifier feedback: 20M, $0.005 \mathrm{mfd}$.

Figure 3. Linearity of visible photometer

Wavelength: $464 \mathrm{~nm}$

Sample size: I $I \mu$ of methyl orange concentration which

is indicated on abscissa

Flow rate: $1.10 \pm .01 \mathrm{ml} / \mathrm{min}$.

slope $=3.03 \times 10^{5} \mathrm{~cm}^{2}$ liter mole

Intercept $=0.55 \mathrm{~cm}^{2}$ 


\section{List of Components}

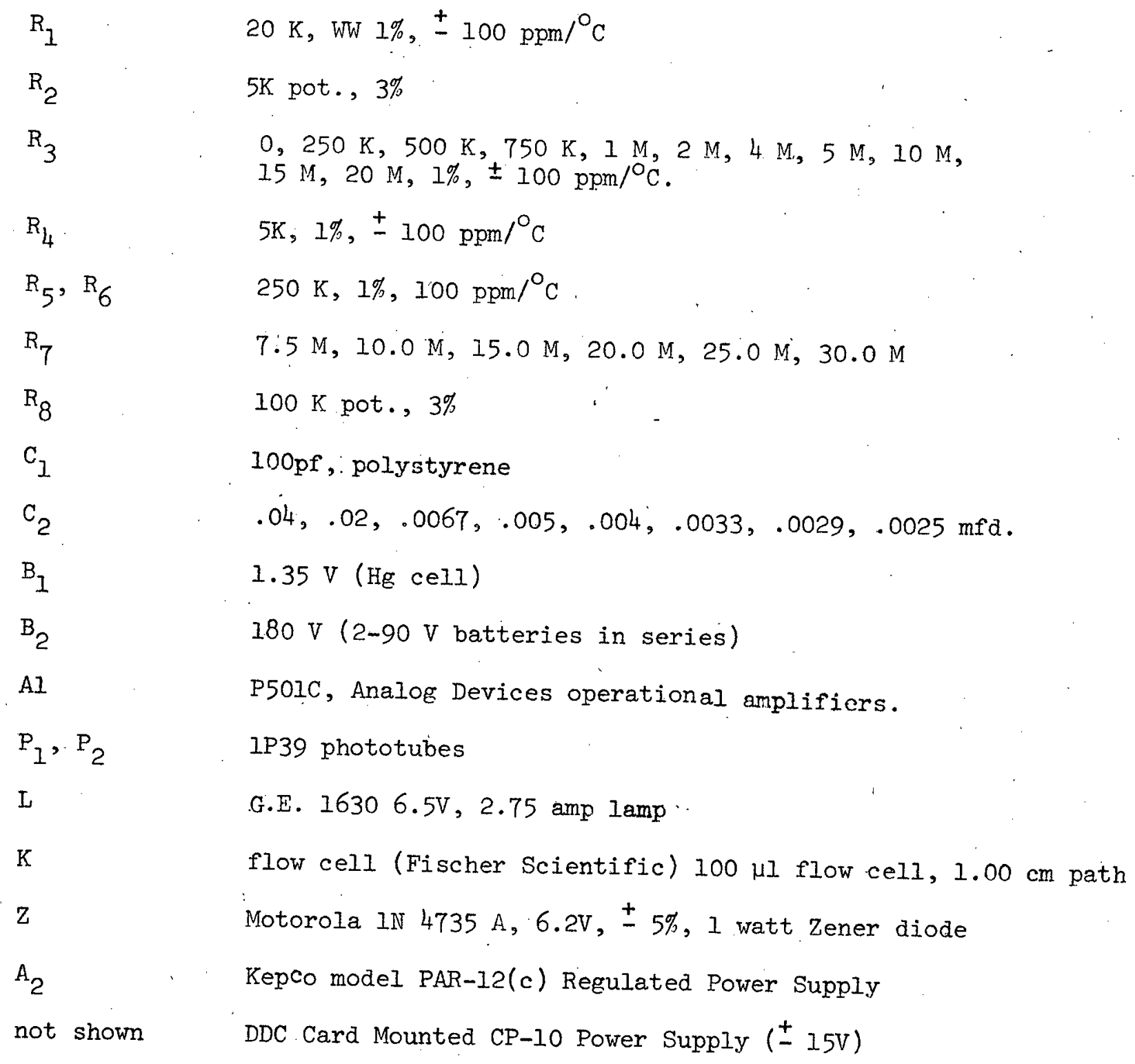




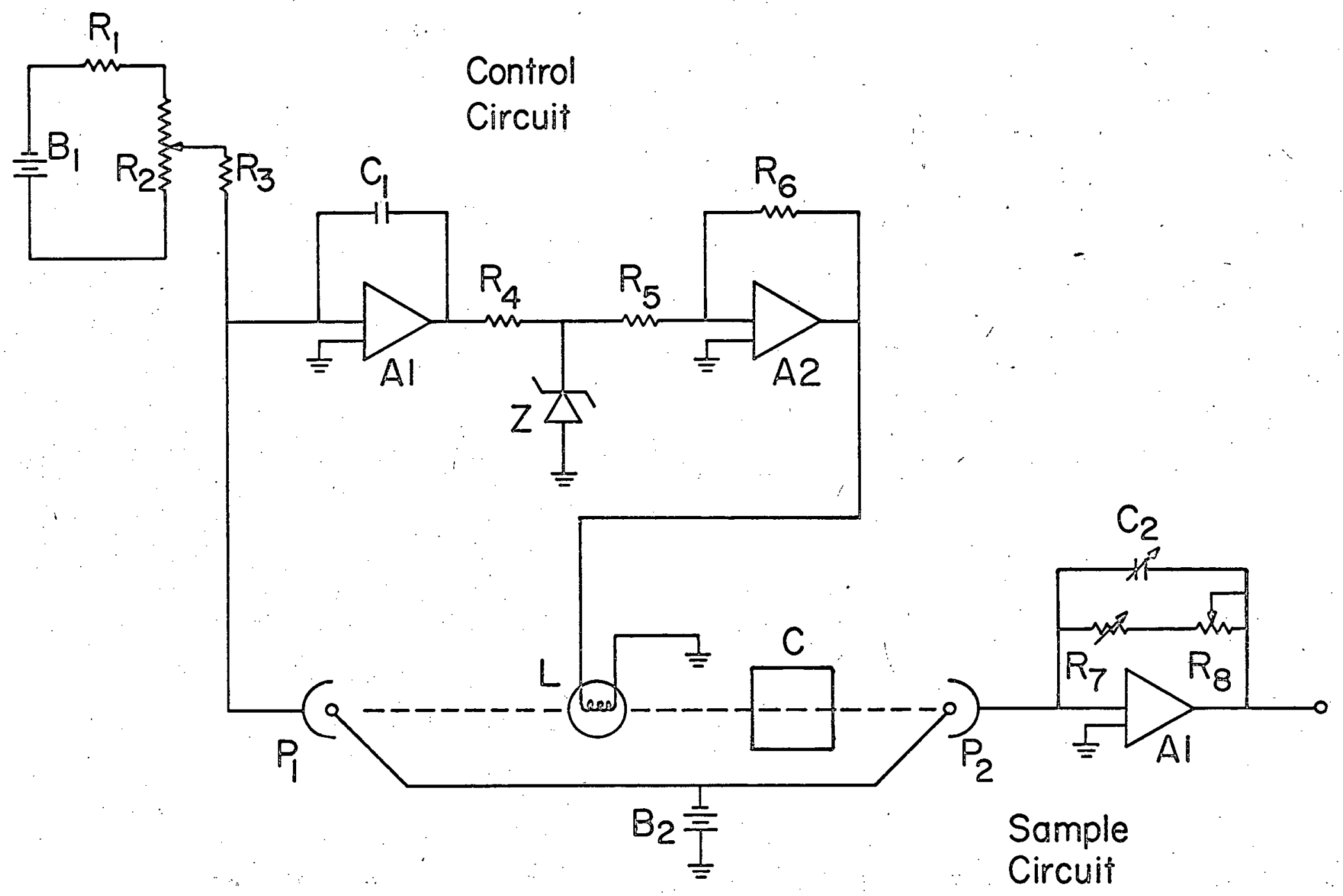




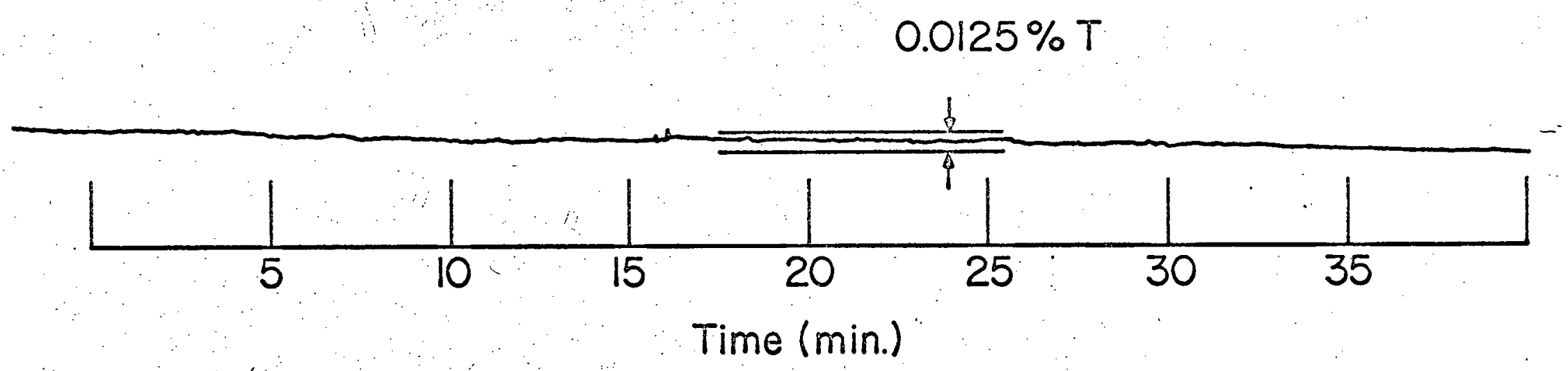




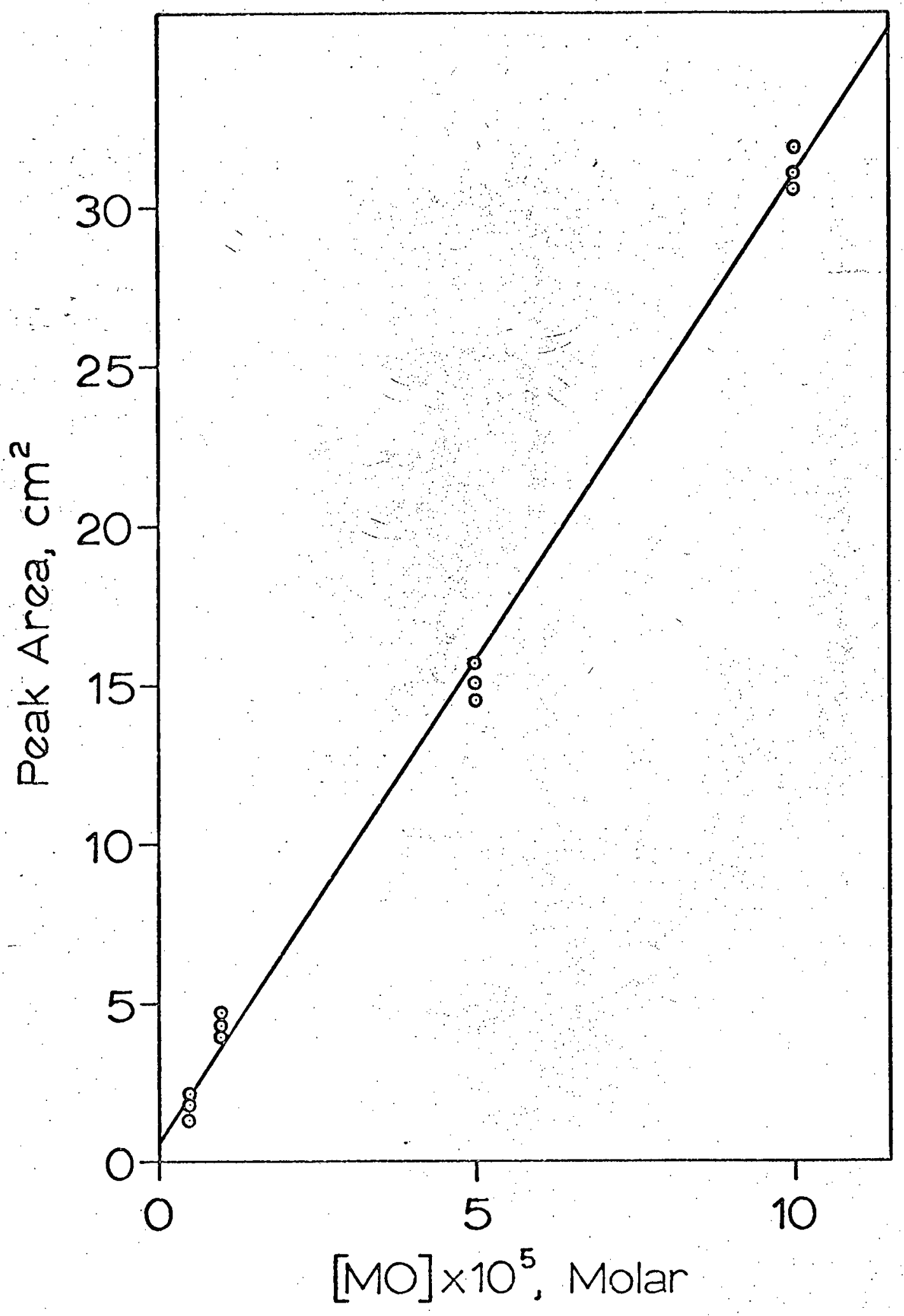

